\title{
INSTITUICÕES DE ATENDIMENTO A CRIANÇAS E ADOLESCENTES EM SITUAÇÃO DE RUA ${ }^{1}$
}

\author{
Juliana Prates Santana \\ Universidade do Minho \\ Thaís Mesquita Doninelli \\ Raquel Valiente Frosi \\ Sílvia Helena Koller \\ Universidade Federal do Rio Grande do Sul
}

RESUMO: o presente estudo visou à descrição das instituições de atendimento a crianças e adolescentes em situação de rua da cidade de Porto Alegre a partir da análise dos documentos escritos produzidos por estes locais e das respostas de um questionário aplicado aos dirigentes institucionais. Esta análise possibilitou uma melhor compreensão dos serviços de atendimento, que são importantes contextos desenvolvimentais para os meninos e meninas em situação de rua. Os resultados demonstram haver contradições entre os documentos e a realidade institucional. Isto se deve, principalmente, ao fato dos documentos não acompanharem as mudanças sofridas pelas instituições, tornando-se, muitas vezes, obsoletos. É importante ressaltar a relevância da análise documental, pois esta possibilita o entendimento de uma série de valores e ideologias assumida pelas instituições. Trata-se, inclusive, de uma relevância histórica que permite compreender como as instituições se organizam para lidar com a questão das crianças e dos adolescentes em situação de rua.

PALAVRAS-CHAVE: instituições de atendimento; crianças e adolescentes em situação de rua; documentos institucionais.

\section{SERVICE INSTITUTIONS FOR STREET CHILDREN AND ADOLESCENTS}

ABSTRACT: This study sought to describe Porto Alegre's service institutions to street children and adolescents based on written documents produced by these institutions and the answers to a which are very important developmental contexts for this population. The results showed that there are some contradictions between the documents and institutional reality. This is due, mainly, to the fact that the documents did not follow-up on institutional changes, usually becoming obsolete. It is important to emphasize the relevance of the documental analysis, since this enables to understand a series of values and ideologies assumed by the institutions. Also, institutional aspects expressed in the documents are historically relevant, allowing for a better comprehension of the institutions, how they organize themselves to work with issues about street children and adolescents.

KEYWORDS: service institutions; street children and adolescents; institutional documents.

Historicamente, as sociedades buscam organizar-se através de instituiç̃es, sendo que as características e objetivos institucionais variam de acordo com as concepções sociais vigentes e as pessoas a quem se destinam. Contudo, o papel social desempenhado por estas instituições parece ter um aspecto comum, baseado na transferência de responsabilidade da sociedade para a instituição específica que foi construída. Este papel social deve ser ressaltado não para retirar o valor que as instituições possuem ou o mérito da realização dos seus trabalhos, mas para enfatizar a relação que a sociedade em geral desenvolve com estas, ajudan- do, assim, a compreender as exigências, as expectativas e as demandas que são depositadas nestes locais.

Em relação às crianças e aos adolescentes em situação de rua, considerados conseqüências dos problemas sociais, uma das soluções encontradas foi a criação de instituições específicas para esta população. Estas instituições acompanharam as mudanças conceituais referentes à infância ao longo do tempo, mas mantiveram sempre o objetivo de atender esta população, especialmente para que não ficassem expostas à visão das pessoas nas ruas. Inicialmente, as instituições eram depósitos 
Santana, J.P.; Doninelli,T.M; Frosi, R.V.; Koller, S.H. "Instituições de atendimento a crianças e adolescentes em situação de rua"

de crianças abandonadas, passando a ser locais de detenção e correção de "menores" infratores ou locais basicamente assistencialistas, que visavam à salvação ou à recuperação destes jovens (ALVIM \& VALLADARES, 1988). Estas funções institucionais, assim como suas características foram alteradas, principalmente, com a implementação do ECA (1990). Desde então, as instituições tiveram que passar por adaptações e têm sofrido mudanças que, no entanto, ainda não foram suficientes para atender às exigências deste estatuto.

É importante destacar que o ECA (1990) ainda não está totalmente incorporado à concepção de infância e adolescência socialmente vigente, podendo esta não-incorporação ser justificada pela sua própria construção. $\mathrm{O}$ processo de atualização deste Estatuto deu-se de forma peculiar, partindo de uma proposta do Movimento Nacional dos Meninos e Meninas de Rua e outras organizações civis, que foi adequada e aprovada pelo Congresso Nacional quando este vivenciava um clima de mudanças pós-constituinte. Revelou-se um processo com ampla participação da sociedade civil organizada, caracterizando-se em um avanço se comparado a projetos de leis anteriores. Contudo, em termos de representatividade social ainda deixou muito a desejar, fazendo com que a noção de crianças e adolescentes como sujeitos de direitos e deveres ainda não seja compartilhada por parte da sociedade, conforme dito anteriormente. Com isto, muitas vezes exige-se do poder público soluções enérgicas contra estas crianças e adolescentes, geralmente no sentido de puni-las, sem a intenção de garantir os seus direitos. A sociedade almeja que os jovens sejam retirados dos locais públicos, deixando, assim, de serem vistos e encarados como um problema social a ser resolvido, pois acredita que ao colocar as crianças e os adolescentes em instituições que, de certa forma escondem o problema, isenta-se de sua responsabilidade. Desta forma, muitas vezes as instituições de atendimento que são promotoras de atividades que respeitam os direitos das crianças são acusadas de não serem efetivas, justamente por não confiná-las em algum local específico. $O$ processo de construção e atualização do ECA, no entanto, tem sido uma preocupação dos profissionais ligados à proteção de crianças e adolescentes, que visam a sistematicamente ampliar a garantia de que estes meninos e meninas são cidadãos de direitos e deveres e estão em desenvolvimento.

A relevância das instituições de atendimento às crianças e adolescentes em situação de rua não é verificada apenas pela sociedade, mas também pelos meninos e meninas que freqüentam es- tes locais (SANTANA, DONINELLI, FROSI, \& KOLLER, 2003). Estudos têm demonstrado a capacidade de envolvimento destes jovens com as instituições, salientando que estes locais, juntamente com seus funcionários, desempenham um importante papel na rede de apoio social e afetivo dos atendidos (BRITO, 1999; FORSTER, BASTOS, TANNHAUSER \& TANNHAUSER, 1992).

Atualmente há em algumas cidades brasileiras e, especialmente no município de Porto Alegre, uma tentativa de atender às crianças e aos adolescentes em situação de rua de forma integral, unificando esforços governamentais e ações da sociedade civil organizada. O discurso predominante demonstra o entendimento de uma noção de criança e adolescente conforme prescrita no ECA (1990), que ressalta a importância do atendimento conjunto ao jovem, pois apenas desta forma todas as suas necessidades podem ser satisfeitas e as ações desenvolvidas podem ser consideradas efetivas. Trata-se de um avanço conceitual que, quando operacionalizado, apresenta possibilidades de alcançar um caráter preventivo, uma vez que deveria, a princípio, enfatizar as razões desencadeadoras do processo de exclusão a que estas crianças e adolescentes, juntamente com suas famílias, foram submetidas.

Neste cenário, as instituições de atendimento às crianças e aos adolescentes em situação de rua possuem como objetivo além do suprimento das necessidades básicas dos jovens atendidos, a promoção de cidadania. É importante enfatizar que acrescentar a promoção de cidadania como objetivo institucional parece ser um reflexo da implementação do ECA (1990), e que foi verificado em alguns estudos com instituições de atendimento (CÂMARA, MEDEIROS, FERRIANI \& GOMES, 2000; HECHT, 1998). Nestes estudos, a noção de cidadania aparece expressa de variadas formas, incluindo a idéia de "superação da condição de violação de direitos e deveres", "reconstrução de identidade social" e "ingresso na comunidade".

Este objetivo de promover cidadania, que muitas vezes não é operacionalizado, traz consigo uma alta responsabilidade social para os que se propõem a esta tarefa. É realmente difícil falar em cidadania para um jovem que já não acredita, e nem poderia acreditar, no sistema social em que está inserido. Não se pode falar em direitos quando se nega comida, nem em obediência às normas sociais quando se e está excluído deste sistema. Enfim, não se pode cobrar os deveres cidadãos de um jovem que não tem a maioria dos seus direitos respeitados. 
Com o intuito de melhor compreender os objetivos das instituições de atendimento às crianças e aos adolescentes em situação de rua em Porto Alegre, este estudo visa a descrever quatro destas instituições, a partir da análise dos documentos escritos produzidos por estes locais e das respostas de um questionário aplicado aos dirigentes institucionais. Tal descrição aborda os objetivos, a estrutura e o funcionamento das instituições, apontando congruências e discrepâncias entre os dados verificados nos documentos e as práticas institucionais descritas pelos dirigentes e observada pelas pesquisadoras.

\section{CONSIDERAÇÕES TEÓRICO-METODOLÓGICAS DA INVESTIGAÇÃO}

Para executar este trabalho foi utilizada como arcabouço teórico e metodológico a Abordagem Ecológica do Desenvolvimento Humano (AEDH), proposta por Bronfenbrenner (1979/1996, 1989, 1993, 1994, 1995a, 1995b, 1999 BRONFENBRENNER \& EVANS, 2000; BRONFEN BRENNER \& MORRIS, 1998), especialmente no que se refere à inserção ecológica da equipe de pesquisa no contexto da instituição. Tal inserção envolve a sistematização dos quatro aspectos fundamentais da AEDH - o processo, a pessoa, o contexto e o tempo.

A inserção ecológica envolve o estabelecimento de processos proximais entre a equipe de pesquisa e os participantes do estudo. De acordo com Bronfenbrenner e Evans (2000) tais processos envolvem uma "transferência de energia entre a pessoa em desenvolvimento e as pessoas, os objetos e os símbolos no ambiente imediato." (p. 118). Para estes autores, tal transferência de energia é que possibilita o desenvolvimento das partes envolvidas nesta interação. No contexto de pesquisa, isto significa que pesquisadores e participantes estabelecem uma relação que, se considerada positiva, permite a aquisição de competências. Esta competência, quando se refere ao pesquisador, se traduz em um melhor conhecimento da realidade investigada.

Bronfenbrenner (1999) estabeleceu uma série de critérios para garantir a concretização dos processos proximais em um setting de pesquisa. A equipe seguiu estes preceitos, engajando-se em atividades informais ou formais, dentro da rotina das instituições. Tal interação deve ter uma certa regularidade, através de períodos estendidos de tempo, e não apenas durante atividades meramente ocasionais. A equipe esteve disponível durante todo o tempo da pesquisa e não apenas durante a cole- sicologia \& Sociedade; 16 (2): 59-70; maio/ago..2004 ta de dados propriamente dita, possibilitando um contato freqüente com o contexto de investigação. A complexidade destas atividades foi progressivamente crescente. Além da interação dos pesquisadores com os participantes, há o estabelecimento de processos proximais entre os integrantes da equipe de pesquisa, possibilitando uma triangulação de informações.

\section{PARTICIPANTES}

Participaram deste estudo quatro instituicões de atendimento a crianças e adolescentes em situação de rua: um albergue noturno, uma escola, um serviço de atendimento de saúde e um alojamento diurno. As instituições foram selecionadas por serem as mais citadas pelos adolescentes participantes do estudo realizado por Santana (2003) e que precedeu a realização do presente estudo. Foram analisados os documentos escritos produzidos por estas instituições e que foram disponibilizados aos pesquisadores. Estes documentos são manuscritos não publicados que contêm a descrição da estrutura, do funcionamento e dos objetivos destes locais. A referência completa de cada um destes documentos não foi listada no final deste texto, pois desvelaria a identidade de cada instituição, descumprindo o compromisso de sigilo assumido pela equipe de pesquisa.

Do albergue noturno analisou-se o Projeto de Abertura (2001). Da escola, foram utilizados: a sua descrição dentro da Análise Diagnóstica do Programa Municipal, o Regimento Escolar e o Plano Anual (2000). A Análise Diagnóstica do Programa Municipal (2000) também embasou a descrição do serviço de atendimento de saúde. Para o alojamento diurno foi utilizado o Projeto de Funcionamento da Instituição (2002). Além da análise dos documentos, foi aplicado um questionário para o cadastramento das instituições de atendimento a crianças e adolescentes em situação de rua.

\section{INSTRUMENTO}

O questionário utilizado foi adaptado para este estudo a partir do instrumento elaborado pelo Centro Brasileiro de Informações sobre Drogas Psicotrópicas - CEBRID (NOTO E COLS., 1994; SILVA-FILHO E COLS., 1990). O questionário original foi utilizado por Brito (1999) em instituições semelhantes às do presente estudo. Tal instrumento é composto por duas partes distintas, sendo que a primeira delas deve ser respondida por um funcionário da instituição. Esta parte é composta por vinte itens que abordam os seguintes tópicos: identifica- 
Santana, J.P; Doninelli,T.M; Frosi, R.V.; Koller, S.H. "Instituições de atendimento a crianças e adolescentes em situação de rua"

ção institucional, funcionamento administrativo, tipo de atendimento prestado, estrutura física, rotina institucional e características da população atendida. A segunda parte, composta por sete itens, deve ser preenchida pelo pesquisador, sendo destinada à descrição institucional baseada na observação deste. Esta parte contribui para a caracterização do contexto investigado, possibilitando um enfoque ecológico da dinâmica e do funcionamento institucional.

\section{PROCEDIMENTOS}

A realização deste estudo envolveu visitas às instituições participantes, sendo solicitados aos seus dirigentes os documentos escritos produzidos por estes locais. Foram, inicialmente, apresentados os objetivos do estudo e solicitada a participação da instituição. O questionário sobre a instituição de atendimento a crianças e adolescentes em situação de rua foi elaborado de forma a poder ser respondido por qualquer funcionário que possuísse um conhecimento geral do funcionamento institucional. No caso do presente estudo foram respondentes dos questionários os dirigentes institucionais. Este fato pode ser considerado como um aspecto enriquecedor do estudo, já que, a princípio, os dirigentes possuem um amplo conhecimento da estrutura e do funcionamento das instituições.

As instituições foram visitadas em várias ocasiões com o objetivo de inserir ecologicamente a equipe de pesquisa no contexto institucional e, a partir disto, melhor conhecer o funcionamento e a dinâmica destes locais, assim como estabelecer um vínculo com os participantes, aumentando, desta forma, a validade ecológica do estudo. Ou seja, a inserção do pesquisador no ambiente de pesquisa ampliou as possibilidades explicativas do estudo, uma vez que suas impressões puderam funcionar como uma fonte complementar de dados (processo proximal do pesquisador; ver mais detalhes em CECCONELLO \& KOLLER, 2003). Tais impressões foram registradas na segunda parte do questionário anteriormente descrito, auxiliando na compreensão contextualizada dos dados.

\section{RESULTADOS E DISCUSSÃO}

A apresentação dos resultados será feita de forma a integrar os dados obtidos através do questionário para o cadastro de instituições de atendimento a crianças e adolescentes em situação de rua e dos documentos analisados. Esta forma de apresentação foi escolhida visando a uma integração dos dados e ao entendimento das estruturas, objetivos e dinâmicas institucionais.

Um primeiro aspecto a ser analisado refere-se aos objetivos das instituições (albergue noturno, escola, atendimento de saúde, alojamento diurno) presentes nos documentos analisados e as demandas iniciais que justificaram a abertura de cada uma delas. A análise conjunta das demandas que de certa forma originaram as instituições e dos seus objetivos é de extrema importância para a compreensão do papel social que estes locais desempenham. Neste sentido, Alvim e Valladares (1988) afirmam que as instituições são criadas justamente para responder a uma demanda social existente, sendo relevante que se analise a relação entre demandas e objetivos institucionais.

$\mathrm{O}$ albergue noturno foi criado em função de uma lacuna que existia na rede de atendimento municipal em relação ao espaço noturno de proteção a crianças e adolescentes, sendo que o serviço atualmente prestado visa a responder a esta demanda. Neste sentido, os objetivos do albergue noturno são: oferecer espaço para albergagem, garantir o provimento das necessidades básicas de alimentação, banho, descanso e avaliação inicial da saúde, de forma a qualificar e ampliar a rede de proteção à criança e ao adolescente existente na cidade (Projeto de Abertura, 2001). Além disto, o albergue noturno funciona em regime de plantão, abordando crianças e adolescentes em situação de rua a partir da solicitação da população. A escola foi planejada, inicialmente, como o "espaço de ensino responsável pela população de crianças e adolescentes em situação de rua, que se encontravam excluídos do processo educativo" (Análise Diagnóstica do Programa Municipal, 2000). Além do acesso ao conhecimento, a escola visa à "construção de projetos de vida" que possibilitem aos adolescentes serem "sujeitos da sua própria história", a partir da realização de oficinas de trabalho educativo. Nos documentos analisados é possível verificar a forma como os objetivos institucionais foram sendo alterados ao longo do funcionamento da escola, em função das mudanças ocorridas na rede de atendimento municipal. Outro objetivo apontado para a escola pela Análise Diagnóstica do Programa Municipal (2000) refere-se ao papel questionador assumido em relação às políticas de atendimento a estas crianças e adolescentes, descrito como uma "(escola) de atuação político-pedagógico questionadora das políticas de atendimento". Neste sentido, a instituição se posiciona como um espaço que questiona as políticas de atendimento existentes e propõe formas inovadoras para estas políticas. Este objetivo 
é alcançado na medida em que a escola consegue, a partir dos seus questionamentos e reflexões, auxiliar o processo de estruturação do programa municipal em vigor. Isto pode ser verificado a partir da análise da história do programa municipal de atendimento a crianças e adolescentes em situação de rua, descrita no conjunto dos documentos analisados.

O serviço de atendimento de saúde surge, segundo a Análise Diagnóstica do Programa $\mathrm{Mu}-$ nicipal (2000), em função de uma demanda específica que era o crescente uso de substâncias psicoativas por parte das crianças e adolescentes em situação de rua. Os argumentos fundamentamse em dados quantitativos que demonstram a gravidade da situação em que esta população se encontrava e que justificariam a abertura de um espaço destinado prioritariamente à questão referente ao uso e abuso de substâncias psicoativas. O objetivo geral da instituição é a "criação de espaço protegido para crianças e adolescentes usuários de substâncias psicoativas, contemplando ações de saúde, de assistência social, educação e lazer, na perspectiva de ser um momento desencadeador de reinserção social". Este objetivo aparece detalhado a partir de uma lista de objetivos específicos que incluem desde a descrição do acolhimento dos meninos e meninas até a articulação das ações desenvolvidas com a rede de atendimento especifico a crianças e adolescentes em situação de rua e com a rede de saúde.

O estudo detalhado da Análise Diagnóstica do Programa Municipal (2000) e a inserção ecológica da equipe de pesquisa revelam que há uma ampla discrepância entre os postulados deste documento e as práticas institucionais, especialmente no que se refere aos objetivos do serviço de saúde. Segundo o dirigente da instituição, desde o momento da abertura do serviço, estes objetivos vêm sendo "repensados $e$ reconstruídos", enfatizando que hoje a proposta institucional difere bastante da inicial. Uma questão levantada refere-se à demanda que originou o serviço, uma vez que esta continua existindo e, talvez, em maior gravidade do que na época da produção do documento. É possível que o serviço realize, atualmente, atividades que são coerentes com os objetivos reformulados, mas estes ainda não estão registrados em documentos institucionais ou em documentos do programa municipal.

O alojamento diurno faz parte de um conjunto de obras assistenciais religiosas voltadas para o atendimento de crianças e adolescentes carentes, sendo esta instituição responsável prioritariamente pelos jovens em situação de rua. Seus principais objetivos são "acolher a todos os meninos e meninas em situação de risco ou de rua", suprindo "necessidades básicas de alimentação, vestuário, higiene, educação informal, esportes e recreação". A instituição enfatiza a importância do retorno à família e da freqüência a um estabelecimento formal de ensino. Ressalta, também, a "articulação com os outros serviços com vistas a um trabalho em rede, mais completo e eficiente" (Projeto de Funcionamento, 2002).

Uma questão interessante presente no Projeto de Funcionamento do Alojamento Diurno (2002) refere-se ao objetivo de que a instituição deve ser suficientemente interessante para que os jovens retornem a ela. É dada ênfase à possibilidade de atrair as crianças e os adolescentes pela nãoobrigatoriedade de freqüência. Este aspecto é evidentemente diferenciado em sua perspectiva ao ser comparado com instituições de atendimento às crianças e adolescentes que não se encontram em situação de rua e que, mesmo precariamente, ainda estão vinculados à família e à escola. Estes locais se limitam, muitas vezes, a exigir a freqüência dos meninos e meninas, ameaçando expulsá-los quando isto não ocorre. Apenas no momento em que acontece a total subversão das normas sociais, como abandono da escola e afastamento da família, é que se atenta para a necessidade de tornar os locais de atendimento mais atrativos à população que os freqüenta.

Como referido anteriormente, a promoção de cidadania aparece na literatura como um possível objetivo institucional (CÂMARA, MEDEIROS, FERRIANI E GOMES, 2000; HECHT, 1998). É possível apontar aspectos presentes nos documentos das instituições investigadas que sugerem a questão da cidadania como um dos seus objetivos. Neste sentido, pode-se considerar, no caso da escola, que a "garantia de acesso ao conhecimento", assim como a possibilidade de "construção de projetos de vida autônomos" são formas de promoção de cidadania. O serviço de saúde apresenta, por sua vez, conceitos como "reinserção e resignificação social", através da manutenção ou retorno do vínculo com a escola e a família como possíveis sinônimos de cidadania. Além disto, aponta a importância da articulação com órgãos que garantam e defendam os direitos das crianças e adolescentes em situação de rua. Por fim, o alojamento diurno refere-se à "transformação da situação de risco", a partir da aproximação e retorno à família, e da freqüência ao ensino formal. Esta diversidade de termos que expressa os objetivos institucionais foi verificada, 
Santana, J.P; Doninelli,T.M; Frosi, R.V.; Koller, S.H. "Instituições de atendimento a crianças e adolescentes em situação de rua"

também, no estudo realizado por Câmara, Medeiros, Ferriani e Gomes (2000) acerca das instituições de atendimento a crianças e adolescentes em situação de rua em Goiânia. Após apresentadas e discutidas as questões relativas à demanda inicial que originou a abertura das instituições e aos objetivos institucionais, serão apresentadas as características institucionais referentes à capacidade de atendimento, principal fonte mantenedora, tempo de funcionamento e número de funcionários na Tabela 1.

TABELA1

Identificação das Instituições de Atendimento por Tipo de Serviço Oferecido, Capacidade de Atendimento, Fonte Mantenedora, Tempo de Funcionamento e Número de Funcionários

\begin{tabular}{|c|c|c|c|c|}
\hline Instituição & $\begin{array}{l}\text { Capacidade de } \\
\text { atendimento }\end{array}$ & $\begin{array}{l}\text { Principal fonte } \\
\text { mantenedora }\end{array}$ & $\begin{array}{l}\text { Tempo de } \\
\text { funcionamento }\end{array}$ & $\begin{array}{l}\text { Número de } \\
\text { funcionários }\end{array}$ \\
\hline Ibergue noturno & 100 & prefeitura & 1 ano & 28 \\
\hline cola & 45 (15/turma) & prefeitura & 7 anos & 26 \\
\hline imento de saúde & 30 (15/turno) & prefeitura & 2 anos & 17 \\
\hline jamento diurno & 60 (30/turno) & entidade religiosa & 12 anos & 6 \\
\hline
\end{tabular}

A capacidade de atendimento institucional referida nos documentos é extremamente discrepante da capacidade e da ocupação efetivas destes locais. Isto ocorre, muitas vezes, em função das limitações físicas destes ambientes, da impossibilidade dos funcionários e técnicos em atender tal quantidade de crianças e adolescentes e, também, pela incerteza quanto ao número real de atendimentos que será realizado a cada dia, em função da não-obrigatoriedade de freqüência dos jovens. A capacidade destes locais é, na prática, a metade daquela referida nos documentos e apresentada na Tabela 1.

A superestimativa da capacidade de atendimento das instituições está também relacionada ao fato destes locais necessitarem de verbas para a implementação e a manutenção das suas atividades. É sabido que quanto maior a abrangência da instituição, mais facilmente ela será apoiada financeiramente, seja em nível governamental ou nãogovernamental. Trata-se de uma estratégia semelhante àquela de superestimar o número de crianças e adolescentes que estão na rua e que vem sendo amplamente criticada na literatura (BANDEIRA, KOLLER, HUTZ, FORSTER, 1994). O apelo numérico é extremamente forte e, provavelmente, estas instituições não estariam funcionando se afirmassem o número real de jovens que em média as freqüenta. Estratégias deste tipo geram um ciclo vicioso que torna impossível a aplicação de políticas públicas com maior seriedade e compromisso, afinal necessidades superestimadas exigem verbas também superestimadas, demanda que centraliza os recursos financeiros governamentais a um pequeno número de receptores.

Em relação à principal fonte mantenedora das instituições analisadas, três (o albergue noturno, a escola e o atendimento de saúde) são de caráter governamental, sendo que apenas o alojamento diurno é mantido por uma entidade religiosa, estando conveniado à prefeitura. Estas instituições compõe o programa municipal de atendimento a crianças e adolescentes em situação de rua da cidade de Porto Alegre, funcionando em um formato de rede integrada de serviços.

$\mathrm{O}$ tempo de funcionamento das instituições varia desde um pouco mais de um ano até doze anos. Isto diferencia o tipo de organização do local, assim como a produção escrita produzida por cada um deles. Obviamente este não é o único critério a ser levado em consideração nesta diferenciação, uma vez que as instituições possuem estruturas e dinâmicas distintas. Além disto, as constantes transformações ocorridas nas instituições fazem com que este tempo de existência seja extremamente relativo. O alojamento diurno, por exemplo, funciona há doze anos, mas suas características foram totalmente alteradas há dois anos quando a instituição foi transferida de local e seus objetivos e abrangência redimensionados.

Em relação ao quadro funcional de cada instituição é saliente o elevado número de funcionários e técnicos em relação ao número de jovens freqüentadores, sendo que isso contrasta com o que se verifica em instituições que prestam serviços a outras populações. Esta aparente vantagem não é considerada suficiente para nenhuma das instituições participantes, uma vez que todas apontam a dificuldade de atender a população alvo com o quadro profissional que possuem. São constantes os relatos sobre a necessidade de ampliar a quantidade de profissionais atuando na instituição. Esta queixa expressa a forma como estes jovens mobilizam os funcionários, já que mesmo nas situações em que se encontram em igual número, relata-se a dificuldade para o desenvolvimento do trabalho. Expressa, também, a necessidade de capacitação permanente dos funcionários existentes, uma vez que as dificuldades envolvidas neste tipo de trabalho são notórias. Contudo vale o questionamento de quais seriam as outras alternativas possíveis, que não simplesmente o aumento do número de profissionais.

Ainda em relação aos profissionais, é interessante apontar a alta rotatividade dos mesmos, que pode denunciar as dificuldades inerentes a este tipo de atividade. Tal rotatividade prejudica, por sua vez, a continuidade do trabalho que está sen- 
do desenvolvido e a capacitação da própria equipe.

Outra questão a ser apontada refere-se à escolha e ao processo de mudança de coordenação das instituições. Os coordenadores do albergue noturno, do atendimento de saúde e do alojamento diurno assumem estes cargos através de indicações, sendo que na escola funciona o regime de eleição, através da consulta à comunidade escolar. A rotatividade dos dirigentes no atendimento de saúde e no alojamento diurno tem sido expressiva nos últimos dois anos. Estes locais encontram-se, respectivamente, em sua terceira e segunda direção no referido espaço de tempo. O dirigen te é, em todos as instituições analisadas, uma figura influente e determinante para a estruturação institucional. Em função disto, as mudanças na direção assumem importância na identidade da instituição uma vez que cada novo dirigente realiza alterações que aproximam as características da instituição às suas concepções de prática institucional. Com a mudança de coordenação, altera-se também o quadro de funcionários, gerase novas discussões acerca de objetivos, entre outras questões. Isto acarreta, muitas vezes, em uma descontinuidade do trabalho que vem sendo desenvolvido, sendo que isto poderia ser minimizado através de uma transição progressiva entre as gestões, na qual o substituto é preparado aos poucos dentro do contexto da instituição para assumir o cargo.

Para compreender melhor o funcionamento e os tipos de atendimento que cada uma das instituições se propõe será descrita a rotina das instituições analisadas. Tal descrição foi possibilitada pela inserção ecológica da equipe no contexto institucional. O albergue noturno funciona diariamente das $19 \mathrm{hs}$ às $7 \mathrm{hs}$, sendo que o atendimento começa com a revista dos adolescentes, com o objetivo de evitar que estes acessem o local portando substâncias psicoativas e/ou objetos que possam ser utilizados como armas. Em seguida, ocorre a entrega de roupas para o banho, depois, é oferecido o jantar, seguido po atividades de entretenimento e um lanche mais tarde. Após a última refeição, os adolescentes vão dormir, sendo acordados na manhã seguinte para o café da manhã. Posteriormente, os jovens devem deixar o albergue, sendo que os que desejam ir para as outras instituições vinculadas à rede são conduzidos por um veículo do próprio serviço. O albergue noturno é a única instituição que funciona nos finais de semana, fazendo com que as possibilidades de atendimento nestes dias sejam bastante reduzidas. Este é um aspecto bastante preocupante quando se pensa na continuidade do trabalho desenvolvido pelas instituições, pois, desta forma, os próprios serviços autorizam que o jovem permaneça em situação de rua mesmo que apenas nos finais de semana. Trata-se de certa forma da legitimação do ambiente da rua como espaço de sobrevivência alternativo e, no caso dos finais de semana, complementar ao espaço institucional. A escola funciona de segunda a sexta-feira, das $7 \mathrm{hs} 45$ às $17 \mathrm{hs}$, sendo que no turno matutino ocorrem as aulas e as atividades especializadas (artes, informática ou educação física). No turno vespertino, acontecem as oficinas profissionalizantes de papel reciclado e jardinagem. $\mathrm{O}$ atendimento inicia-se no portão da escola, sendo feito, por uma dupla de educadores, uma revista e o acolhimento das crianças e dos adolescentes. A entrada pode ocorrer até às $9 \mathrm{hs}$, havendo flexibilidade caso sejam apresentadas justificativas para o atraso. Após este acolhimento, é servido o café da manhã, seguido da realização das atividades pedagógicas nas salas de aula. Há, então, um pequeno intervalo que precede a prática das atividades especializadas, sendo encerrado o turno matutino com o fornecimento do almoço. A duração das atividades em sala de aula é de aproximadamente noventa minutos, não havendo rigidez neste horário, pois a escola considera o "tempo de tolerância" dos alunos para permanecerem dentro das salas de aula. A direção afirma que no início das atividades este "tempo" era de apenas dez minutos, mas que foi se estendendo, demonstrando segundo eles "uma maior maturidade das crianças e dos adolescentes". Os módulos de ensino são organizados em totalidades, que é definido, na perspectiva da escola, como uma organização que visa ao acompanhamento dos progressos do aluno, permitindo que este acompanhe as atividades mesmo que ele ingresse em qualquer época do ano letivo. Contudo, esta diferença muitas vezes dificulta a futura adaptação do adolescente em escolas formais. Esta dificuldade, no entanto, não é exclusiva da escola aberta, mas de todas as instituições que trabalham com metodologias de ensino diferenciadas.

O serviço de saúde aponta para a dificuldade de se estabelecer uma rotina, sendo esta mais uma das questões que abrange as discussões acerca da caracterização do serviço. Além disto, há um número expressivo de atendimentos individuais com os profissionais da psiquiatria, pediatria e psicologia, fazendo com que a rotina seja bastante personalizada. A instituição funciona de segunda a sexta-feira, das $7 \mathrm{hs} 30$ às $18 \mathrm{hs} 30$. As atividades coletivas consistem basicamente na entrada e saí- 
Santana, J.P; Doninelli,T.M; Frosi, R.V.; Koller, S.H. "Instituições de atendimento a crianças e adolescentes em situação de rua"

da dos meninos e meninas, nas refeições e banho. O alojamento diurno funciona de segunda a sexta-feira, das $8 \mathrm{hs}$ às $17 \mathrm{hs}$, iniciando suas atividades com o café da manhã, seguido de atividades esportivas realizadas na praça em frente à instituição. Após estas atividades, os meninos e meninas tomam banho, participam de atividades pedagógicas e almoçam. Depois de um período de descanso ou atividades de entretenimento com "baixo nível de agitação", os jovens participam de atividades diversas, que incluem dança, capoeira, jogos de mesa, etc. Estas atividades são seguidas de lanche, posterior ida à sala de jogos e encerramento do atendimento do dia.

É importante discutir a relação entre os horários de funcionamento das diferentes instituições, pois se observa a existência de algumas lacunas entre os períodos de saída e entrada de alguns destes serviços. A saída dos adolescentes do albergue noturno, por exemplo, ocorre às $7 \mathrm{hs}$, sendo que o veículo do serviço os deixa em frente ao alojamento diurno em aproximadamente trinta minutos. No entanto, o atendimento desta instituição inicia-se apenas às 8hs, deixando os adolescentes na rua durante trinta minutos. Este tempo é suficiente para que eles se dispersem, saindo da frente do alojamento diurno, em geral, com o intuito de usarem substâncias psicoativas ou mesmo por desistirem de acessar o serviço. Maior intervalo de tempo ocorre entre a saída do alojamento diurno e o início do atendimento do albergue noturno. Trinta minutos pode parecer pouco tempo, mas o fato de deixar este jovem justamente no espaço da rua chama a atenção. A rua é considerada pelas instituições, exatamente, como o seu maior concorrente. Além disto, é necessário questionar qual criança e/ou adolescente esperaria este tempo para entrar na escola se tivesse a opção de fazer qualquer outra atividade que considerasse mais atrativa.

Ainda em relação às rotinas institucionais, é importante ressaltar a necessidade de adequálas ao quotidiano das crianças e dos adolescentes em situação de rua. Koller (2001), ao discutir sobre as características das escolas destinadas a esta população, aponta a importância destes ajustes para a efetividade dos serviços. Obviamente, não se trata apenas de acertos acerca das normas de funcionamento, como dos horários de entrada e saída, mas do reconhecimento, por parte das instituições, das peculiaridades vivenciadas por estes jovens e que são determinadas pelo estar na rua. Pôde-se observar que as instituições analisadas levam em consideração as características desta população, uma vez que se preocupam, entre outras coisas, em construir estratégias de ação voltadas especificamente para este público.

Outro aspecto investigado foi a estrutura física das instituições, sendo esta observada durante as visitas e ressaltada, em muitos momentos, pelos integrantes da instituição. Cada local estudado possui características físicas bastante peculiares que merecem ser enfatizadas.

O alojamento diurno possui uma excelente estrutura física, totalmente reformada e bem equipada. Segundo o respondente do questionário, este aspecto físico é fundamental para que as crianças e adolescentes que freqüentam a casa se sintam valorizados e consigam diferenciar a instituição de qualquer outro espaço. Na escola este elemento também aparece, já que sua estrutura física é bastante cuidada, tendo sido elaborada conjuntamente com as crianças e os adolescentes em situação de rua na época da construção do espaço, em 1994.

O albergue noturno possui instalações amplas e equipadas, mas bastante simples. O espaço assemelha-se à rua, seja pela pouca luminosidade do local, seja pela ausência de pintura nas paredes. Isto não se aplica ao refeitório, quartos, banheiros, mas principalmente à área existente entre estes outros ambientes. Ver os adolescentes sentados nos muros ou nos degraus de uma escada dentro da instituição é como vê-los sentados na rua. Esta semelhança pode ser considerada positivamente, uma vez que os adolescentes podem se sentir menos desconfortáveis em freqüentar um espaço que não se difere muito daquele que costumam freqüentar. E interessante que os coordenadores apontam que, em um primeiro momento, muitos jovens dormem na instituição como se estivessem na rua, ou seja, dormem no chão, em posição fetal, cobrindo os rostos com as camisas. Ao mesmo tempo, a semelhança do espaço institucional com a rua pode dificultar que o adolescente rompa com o vínculo que possui com esta, iniciando, mas não finalizando, o processo de "desrualização".

O serviço de atendimento de saúde possui uma estrutura física bastante inadequada para a realização de suas atividades. Trata-se de um sobrado com cinco andares, sendo que a verticalidade da instituição faz com que a movimentação em seu interior seja muito difícil. A maioria dos andares não possui janela e há apenas uma porta de saída, gerando, inclusive, problemas de segurança em casos de emergência. A Análise Diagnóstica do Programa Municipal (2000), por sua vez, aponta que a instituição deveria contemplar ambientes mais adequados, sendo importante ressaltar que se trata de uma estrutura provisória enquanto a 
sede definitiva não está pronta.

Ainda em relação à estrutura física das instituições, é importante ressaltar que a sua adequação às necessidades das crianças e adolescentes atendidas está prevista pelo ECA (1990), visando à garantia da integridade destes jovens. Pôde-se constatar que as instituições participantes respeitam as condições de salubridade, higiene e segurança previstas pelo estatuto. Dados semelhantes foram encontrados por Câmara, Medeiros, Ferrian e Gomes (2000), que apontam a importância do espaço físico destes locais para a execução adequada do trabalho proposto.

Finalizada a descrição das instituições no que se refere à sua estrutura e dinâmica de funcionamento, serão apresentadas as características da população atendida nestes locais. A análise destas características contribui para um melhor entendimento da própria instituição, uma vez que é possível, a partir disso, avaliar a adequação dos objetivos e práticas institucionais à população a que se destina.

A faixa etária dos freqüentadores das instituições consiste, principalmente, de jovens de doze a dezesseis anos, havendo diferenças em termos da idade prevista para atendimento em cada um dos locais. Esta faixa etária é descrita na literatura como sendo a de maior freqüência entre os meninos e meninas em situação de rua (APTEKAR, 1996; MACIEL, BRITO, CAMINO, 1997; MARTINS 1996; YUNES, ARRIECHE, TAVARES, 1997). O albergue noturno, a escola e o serviço de atendimento de saúde prevêem o atendimento de jovens com idades entre sete e dezoito anos incompletos. $O$ alojamento diurno prevê o atendimento de jovens de sete a dezesseis anos incompletos. É importante comentar duas questões acerca da idade da população prevista para atendimento. A primeira delas refere-se à amplitude desta faixa etária, uma vez que ao englobar diversas fases desenvolvimentais são necessárias atividades específicas que se adeqüem a cada uma destas etapas. Verificou-se, durante a realização do presente estudo, uma dificuldade das instituições em proporcionar atividades variadas que abarquem toda a faixa etária atendida. A segunda questão a ser comentada é o aumento de conflitos entre os freqüentadores das instituições quanto maior a diferença etária existente entre eles. Tais conflitos são citados, muitas vezes, pelos meninos e meninas como motivos para deixarem de freqüentar uma determinada instituição (SANTANA, 2003).

Em relação ao sexo das crianças e dos adolescentes atendidos pelas instituiç̃es, há uma predominância do sexo masculino, o que apenas reflete a predominância deste gênero da população em situação de rua, já revelada na literatura (RAFFAELLI E COLS., 2000, 2001). Apesar desta característica evidente, é possível constatar que, de maneira geral, as instituições encontram-se preparadas e equipadas para receber as poucas meninas que as freqüentam. Ressalta-se aqui a qualidade dos ambientes destinados às meninas tanto no albergue noturno como no alojamento diurno. Estes possuem espaços decorados com objetos socialmente considerados femininos, tais como espelhos, bichinhos de pelúcia, etc. Há, inclusive, diferenças nas regras de organização dos dormitórios para cada sexo. As meninas possuem suas próprias camas, sendo que os meninos escolhem uma cama a cada dia, por ordem de ingresso. É evidente que esta forma de organização é mais fácil no caso das meninas, uma vez que elas são minoria entre os atendidos pelas instituições.

Outra característica dos meninos e meninas em situação de rua que freqüentam as instituições analisadas é a irregularidade com que freqüentam estes locais. Este dado é apontado sistematicamente por todos os dirigentes questionados. Entretanto, é possível constatar que o acesso de novos jovens é relativamente escasso, demonstrando que esta rotatividade ocorre dentro de um grupo conhecido de meninos e meninas. Esta inconstância na freqüência às instituições é apontada pelos dirigentes como um dos fatores que dificultam a efetividade do serviço como um todo. Trata-se de um desafio constante, pois significa conseguir ser suficientemente atraente para que estes jovens retornem e, ao mesmo tempo, propor atividades cuja continuidade não seja requisito indispensável. Ou seja, atividades cuja finalidade seja alcançada no dia da sua realização, sem necessariamente exigir a presença do adolescente na atividade seguinte. Contudo esta ausência de assiduidade é prevista por todos os locais que pretendem trabalhar com jovens em situação de rua, não podendo ser a única justificativa para a nãoefetividade das instituições.

Após a apresentação e discussão das características da população atendida pelas instituições, é importante apontar de que forma estes locais prevêem a avaliação do serviço que realizam. Apenas nos documentos do serviço de atendimento de saúde e do alojamento diurno estão previstas as formas de avaliação, sendo que em ambos a avaliação prevista é mensal, através das reuniões de equipe (Análise Diagnóstica do Programa Municipal, 2000; Plano de Funcionamento, 2002). O atendimento de saúde prevê, ainda, a avaliação do impacto social do programa desenvolvido pela 
Santana, J.P.; Doninelli,T.M; Frosi, R.V.; Koller, S.H. "Instituições de atendimento a crianças e adolescentes em situação de rua"

instituição e a presença de avaliadores externos que pudessem auxiliar neste processo avaliativo. Apesar da avaliação ser prevista apenas nestas duas instituições (atendimento de saúde e alojamento diurno), em todos os serviços ocorrem discussões periódicas, aparentemente com caráter avaliativo, havendo reuniões semanais em cada um das instituições e quinzenais enquanto proposta do programa municipal. Seria necessário acompanhar ou investigar melhor o teor destas reuniões para identificar os assuntos que ali são tratados e se efetivamente é conseguido, nestes espaços, ultrapassar as questões quotidianas havendo uma real avaliação do impacto e da eficácia dos serviços. Neste tipo de serviço parece fácil que coordenadores, funcionários e técnicos sejam totalmente absorvidos pela rotina com as criancas e adolescentes. As vicissitudes do trabalho, apontadas pelos respondentes dos questionários e verificadas pelos pesquisadores, assumem um caráter tão emergencial e essencial que se torna difícil um desprendimento deste quotidiano para uma discussão mais ampla que abranja a avaliação do real impacto destes serviços.

Ao se analisar as instituições participantes deste estudo, constatou-se a influência que a estrutura de rede deste programa exerce na organização de cada serviço. Esta estrutura influencia, inclusive, a forma como os documentos das instituições são elaborados. Analisados isoladamente são documentos pobres que não apresentam os objetivos de reinserção social que aparece nos discursos institucionais. Aparentemente tal objetivo seria delegado à rede, sendo que esta passa a ser muito mais do que a simples união dos serviços e assume uma existência própria. Este tipo de funcionamento em rede já foi objeto de estudo (DAL MOLIN, 2002), sendo interessante que o mesmo fosse feito especificamente em relação a este programa municipal. É importante ressaltar que o funcionamento das instituições em forma de rede é referido em outros estudos como sendo o ideal para o atendimento dos jovens em situação de rua (CÂMARA, MEDEIROS, FERRIANI, \& GOMES, 2002; CÂMARA, MORAES, MEDEIROS, \& FERRIANI, 2000; MEDEIROS \& FERRIANI, 1995). O funcionamento em rede é, portanto, um avanço em relação às políticas de atendimento, existentes na maioria dos municípios brasileiros.

A pobreza dos documentos é algo a ser comentado e discutido com maior cuidado, uma vez que envolve uma série de outras questões institucionais. Os serviços possuem uma dinâmica extremamente veloz que não consegue ser acompanhada pelos registros escritos. Com certeza, tra- ta-se de um problema para a análise do próprio processo histórico das instituições, sendo que tal análise contribuiria enormemente para o aperfeiçoamento destes locais. Entretanto, a ausência de documentos escritos atualizados não parece representar uma falta de reflexão acerca do trabalho da instituição, mas uma sobrecarga de trabalho. Sabese que o processo de elaboração e construção de um documento, principalmente de caráter coletivo, demanda uma grande quantidade de tempo e de energia daqueles que se propõem a executar tal tarefa. Talvez este trabalho seja considerado pelos integrantes das instituições como possuindo um valor secundário ao cumprimento das tarefas quotidianas. Contudo, não se pode negar a importância de tais registros, ressaltando-se que o próprio processo de construção destes documentos seria um momento de repensar e qualificar a prática institucional.

As autoras agradecem às instituições participantes do estudo, pelo apoio e disponibilidade.

NOTA

${ }^{1}$ Esse estudo faz parte da Dissertação de Mestrado em Psicologia do Desenvolvimento (UFRGS) da primeira autora, orientada pela última autora.

\section{REFERÊNCIAS}

ALVIM, M. R. B.; VALLADARES, L. P. Infância e sociedade no Brasil: Uma análise da literatura. BIB: Revista Brasileira de Informação Bibliográfica em Ciências Sociais. São Paulo, v. 26, p. 3-37, 1998.

APTEKAR, L. Crianças de rua nos países em desenvolvimento: Uma revisão de suas condições. Psicologia: Reflexão e Crítica. Porto Alegre, v. 9, p.153184, 1996.

BANDEIRA, D. R.; KOLLER, S. H.; HUTZ, C. S.; FORSTER, L. O cotidiano de meninos e meninas de rua. XVII International School Psychology Colloquium. Campinas, São Paulo, 1994.

BRONFENBRENNER, U. Ecological systems theory. Annals of Child Development, Oxford, v. 6, p. 187249, 1989.

BRONFENBRENNER, U. The ecology of cognitive development: Research models and fugitive findings. In: WOZNIAK, R. H.; FISCHER, K. Development in context: Acting and thinking in specific environments. Hillsdale, NJ: Erlbaum, 
1993. p. 3-44.

BRONFENBRENNER, U. Ecological Models of Human Development. International Encyclopedia of Education. England: Elsevier Sciences, v. 3, p. 1643-1647, 1994

BRONFENBRENNER, U. Bioecological model from a life course perspective: Reflections of a participant observer. In: MOEN, P. M.; ELDER, G. H. LÜSCHER, K. Examining lives in context. Washington, DC: American Psychological Association, 1995a. p. 599-618.

BRONFENBRENNER, U. Developmental ecology through space and time: A future perspective. Em MOEN, P. M.; ELDER, G. H.; LÜSCHER, K. Examining lives in context. Washington: American Psychological Association, 1995b. p. 619-648.

BRONFENBRENNER, U. A ecologia do desenvolvimento humano: Experimentos naturais e planejados. $1^{\text {a }}$. ed. Porto Alegre: Artes Médicas, 1996. (Originalmente publicado em 1979)

BRONFENBRENNER, U. Environments in developmental perspective: Theoretical and operational models. In: FRIEDMAN, B. L.; WACKS, T. D. Conceptualization and assessment of environment across the lifespan. Washington, DC American Psychological Association, 1999. p. 3-30.

BRONFENBRENNER, U.; EVANS, G. W Developmental science in the $21^{\text {st }}$ century: Emerging Questions, theoretical models, research designs and empirical findings. Social Development, Chicago, v. 9, p. 115-125, 2000.

BRONFENBRENNER, U.; MORRIS, P. The ecology of developmental processes. In: DAMON, W. Handbook of child psychology. New York: John Wiley \& Sons, v. 1, p. 993-1027, 1998.

CÂMARA, M. F. B.; MEDEIROS, M.; FERRIANI, M.G.C.; GOMES, R. O abandono social da infância e adolescência na ótica dos coordenadores de instituições de assistência a crianças e adolescentes em situação de rua na cidade de Goiânia. $R e$ vista Brasileira de Crescimento e Desenvolvimento Humano. São Paulo, v. 12, n. 1, p. 9-16, 2002.

CÂMARA, M. F. B.; MORAES, M. M.; MEDEIROS M.; FERRIANI, M. G. C. (2000). Aspectos da assistência prestada a crianças e adolescentes em situação de rua no município de Goiânia. Revista Eletrônica de Enfermagem. Goiânia, v. 3, n. 1, 2000. Disponível em: <http://www.fen.ufg.br/revista $>$. Acesso em: 14. dez. 2002.

CECCONELLO, A. M. Resiliência e vulnerabilidade em famílias em situação de risco. 2003. Tese (Doutorado em Psicologia do Desenvolvimento). Universidade Federal do Rio Grande do Sul, Porto Alegre, 2003.

DAL MOLIN, F. Autopoiese e sociedade: A rede in tegrada de serviços da Restinga na teoria dos sistemas vivos. 2002. Dissertação (Mestrado em Psicologia Social e Institucional). Universidade Federal do Rio Grande do Sul, Porto Alegre, 2003.

BRASIL. Lei n. 8.069, de 13 de julho de 1990. Estatuto da Criança e do Adolescente. São Paulo: Cortez.

HECHT, T. At home in the street: Street children of northeast Brazil. $1^{\mathrm{a}}$. ed. Cambridge: Cambridge University Press, 1998.

KOLLER, S. H. A escola, a rua e a criança em desenvolvimento. In DEL PRETTE, Z. A. P. Psicologia escolar e educacional: Saúde e qualidade de vida. $1^{\text {a }}$. ed. São Paulo: Editora Alínea, 2001. p. 159176.

MACIEL, C.; BRITO, S ; CAMINO, L. Caracterização dos meninos em situação de rua de João Pessoa. Psicologia: Reflexão e Crítica. Porto Alegre, v. 10, p. 315-334, 1997.

MARTINS, R. A. Censo de crianças e adolescentes em situação de rua em São José do Rio Preto. $P S i-$ cologia: Reflexão e Crítica. Porto Alegre, v. 9, p. 101-122, 1996.

MEDEIROS, M.; FERRIANI, M. G. C. Programas de atenção às crianças e adolescentes em situação de rua: Percepções de seus coordenadores. Revista Brasileira de Crescimento e Desenvolvimento Humano. São Paulo, v. 5, n. 1/2, p. 48-59, 1995.

NOTO, A. R.; NAPPO, S. A.; GALDURÓZ, J. C. F.; MATTEI, R. CARLINI, E. II Levantamento sobre o uso de drogas entre meninos e meninas de rua de cinco capitais brasileiras no ano de 1993. CEBRID - Escola Paulista de Medicina, 1994.

RAFFAELLI, M.; KOLLER, S. H.; REPPOLD, C.; KUSCHICK, M.; KRUM, F.; BANDEIRA, D.; SIMÕES, C. Gender differences in Brazilian street 
Santana, J.P.; Doninelli,T.M; Frosi, R.V.; Koller, S.H. "Instituições de atendimento a crianças e adolescentes em situação de rua"

youth's family circumstances and experiences on the street. Child Abuse \& Neglect, v. 24, n. 11, p. 1431-1441, 2000.

RAFFAELLI, M.; KOLLER, S. H.; REPPOLD, C.; KRUM, F.; BANDEIRA, D. How do street youth experience the street? Analysis of a sentence completion task. Childhood, v. 8, n. 3, p. 396-415, 2001.

ROSEMBERG, F. A concepção de família subjacente a programas para crianças e adolescentes em situação de rua. In: CARLINI, E. A. Abuso de drogas entre meninos e meninas de rua do Brasil. UNFDAC-CEBRID, São Paulo: Editora Ave Maria, 1990. p. $87-90$.

SANTANA, J. P. Instituições de atendimento a crianças e adolescentes em situação de rua: Objetivos atribuídos por seus dirigentes e pelos jovens atendidos. 2003. Dissertação (Mestrado em Psicologia do Desenvolvimento). Universidade Federal do Rio Grande do Sul, Porto Alegre, 2003.

SANTANA, J. P.; DONINELLI, T. M.; FROSI, R.V.; KOLLER, S. H. Os adolescentes em situação de rua e as instituições de atendimento. Manuscrito submetido à Revista Psicologia: Reflexão e Crítica.

SILVA-FILHO, A. R.; CARLINI-COTRIM, B.; CARLINI, E. A. Uso de psicotrópicos por meninos de rua: Comparação entre dados coletados em 1987 e 1989. In: CARLINI, E. A. Abuso de drogas entre meninos e meninas de rua do Brasil. UNFDAC CEBRID, São Paulo: Editora Ave Maria, 1990. p. 119.

YUNES, M. A. M.; ARRIECHE, M. R. O.; TAVARES, M. F. A. Meninos(as) em situação de rua na cidade de Rio Grande: Vida na rua e vida na instituição. Momento, Rio Grande, v. 10, p. 131-142, 1997.

Juliana Prates Santana é Psicóloga graduada pela Universidade Federal da Bahia, Mestre em Psicologia do Desenvolvimento pelo Programa de Pós-Graduação em Psicologia da Universidade Federal do Rio Grande do Sul e Doutoranda em Estudos da Criança, na Universidade do Minho, Portugal. Membro do Centro de Estudos Psicológicos sobre Meninos e Meninas de Rua (CEPRUA/Psicologia/UFRGS) e Doutoranda pela Universidade do Minho, Portugal. o endereço eletrônico da autora é: jps1103@msn.com

Sílvia Helena Koller é Psicóloga, Doutora em Edu- cação (PUCRS), Pesquisadora do CNPq, Professora do Curso de Pós-Graduação em Psicologia do Desenvolvimento da Universidade Federal do Rio Grande do Sul. Coordenadora do Centro de Estudos Psicológicos sobre Meninos e Meninas de Rua (CEP-RUA/Psicologia/UFRGS. O endereço eletrônico da autora é: kollersh@ufrgs.br

Raquel Valiente Frosi e Thaís Mesquita Doninelli são estudantes do Curso de Graduação em Psicologia/UFRGS. Membros do Centro de Estudos Psicológicos sobre Meninos e Meninas em Situação de Rua (CEP-RUA/Psicologia/

UFRGS).

Juliana Prates Santana, Thaís Mesquita

Doninelli, Raquel Valiente Frosi e Sílvia

Helena Koller.

Recebido: 23/4/2004

$1^{\text {a }}$ revisão: $17 / 6 / 2004$

Aceite final: 25/6/2004 